\title{
Study on Activation Mechanism and Sustainable Development of Rural Human Settlements Based on Landscape Construction
}

\author{
Sui $\mathrm{Xin}^{1}$, Lin Lin $* 2$ (Correspondence author), Sun Chaoyang ${ }^{3}$ \\ ${ }^{1}$ Dalian Nationalities University, No. 18, Liaohe West Road, Dalian Economic \& Technical Development Zone, China, 116600 \\ ${ }^{2}$ Lecturer, School of Art and Design, Dalian Polytechnic Univ., Dalian, China, 116034, E-mail : guganmao@126.com \\ ${ }^{3}$ Dalian Nationalities University, No. 18, Liaohe West Road, Dalian Economic \& Technical Development Zone, China, 116600
}

\begin{abstract}
The quality of rural human settlement environment is directly related to the quality of urban human settlements, which is a big problem in the development of China's social economy. In the special period of social transformation and the key stage of building a well-off society comprehensively, it is of great practical significance to pay attention to the optimization of rural human settlement environment. China is in the transition from traditional rural landscape to modern rural landscape. However, how to realize the smooth transformation and the sustainable development of rural landscape is urgent and tough issues.
\end{abstract}

\section{Introduction}

The study of landscape construction based on rural settlements provides a framework and basis for rural landscape construction at the meso- and macro-levels. Based on the construction, landscape and planning disciplines, combined with the core spirit of cognitive development theory, synergetics, communication, psychology and other related theories, through combing the structure level and development thread of subject cognition, the author makes a detailed analysis of the villagers ' cognitive style and evolution characteristics in natural environment, social environment and built environment. The paper hope to play a certain practical guidance significance on the current rural settlement construction.

In the face of the regional cultural aphasia, the degradation of the ecological environment and the absence of root in the spatial form, this paper tries to extract some common meanings, features and laws in the village settlement construction in a way that is open and integrated. Its basic purpose is the cognitive considerations of villagers' subjects, "Seeing the big through the small" caused the rural settlements of the construction method of our thinking and improvement.

\section{The theoretical significance of the study of rural human settlement environment}

The research point of view of rural human settlements environment is the investigation and analysis of the laws and phenomena of rural natural ecological environment, traditional regional culture and regional human settlement space activities. The existing theoretical research on the one hand lacks systematicness, on the other hand, it lacks analysis and comparison under the microscopic perspective. Therefore, research on rural human settlements in underdeveloped areas based on surveys and studies of a large number of informative data is of great significance for the overall development of urban and rural areas and the improvement of the quality of rural development, as well as the improvement of the theoretical system of human settlements.

In the process of rapid urbanization, cities continue to expand into neighboring villages. The traditional rural settlement culture, personal relations, and community awareness are impacted by urban culture and gradually merged and replaced. The rural residential environment is in a state of disorder and transformation, and it urgently needs attention.

\section{The realistic demand of activating the living environment in rural areas}

Rural residential environment is a system of dwelling in rural area, that is, the organic combination of material and immaterial that farmers need to produce and live, is a dynamic complex giant system, its function transformation and evolvement have intrinsic law. The quality of rural human settlement environment is directly

\footnotetext{
* Corresponding author: guganmao@126.com
} 
related to the quality of urban human settlements, which is a big problem in the development of China's social economy. In the special period of social transformation and the key stage of building a well-off society comprehensively, it is of great practical significance to pay attention to the optimization of rural human settlement environment. The new countryside construction provides the planning and the management policy basis for the rural residential area system optimization and the urban-rural coordinated development from the whole angle of view, is also an important way to realize the human settlements environment optimization.

\section{Basic conditions for the study of rural human settlement environment}

The rural human settlement environment and its location of the ecological environment, resources, social and economic has a very close material, energy exchange. These comprehensive environmental elements not only laid the foundation material platform for the development of rural settlements, but also affected the basic characteristics and internal laws of their distribution, form and combination, and finally contributed to the regional differences of rural settlements.

\subsection{Social structure}

With the development of rural economy and urbanization, the rural social structure gradually from the closed to open, from the homogeneous single society to the heterogeneous diversity of the transition and transformation of society, rural social structure began to transition from the traditional to the modern. The factors that promote the change of social structure in rural areas are also varied, which promotes the flow of large numbers of young and middle-aged labors to cities, the loss of rural Labor leads to the hollowing out of rural areas, the reform of production technology, and the related media, etc., which play a role in the process of rural social change

\subsection{Folk culture}

National culture refers to the culture that reflects the national characteristics of the nation in its own historical development process. National culture reflects a nation's historical development level and unique cultural temperament, including material culture, spiritual culture and institutional culture three levels.

\subsection{Spatial structure of settlements}

The rural settlement is influenced by many factors such as natural environment, mode of production and cultural difference, and forms a stable spatial structure pattern in the settlement space. According to the type of spatial structure, it can be divided into rural cluster villages, mostly in the area near the towns, and the linear distribution of rural areas. Most of them along the traffic arteries and linear arrangement. Pastoral diaspora is more distributed in grassland areas, rural homes or several households, or scattered distributed. (regiment, strip and scatter).

\section{The development course of rural human settlement environment}

For the development stage of rural construction, different scholars have roughly divided it into three to four stages according to the research emphases. Ren Qinguo thought that the course of rural construction in China can be divided into three stages of the construction experiment period, the founding to the reform and opening-up period and the later period. Li Jianqiao suggested that 19491978 is the stage of grain, 1979-2005 is the market stage, and 2006 is the stage of development in the new period. Lin Tao used its age as a node, which has made its profile four stages, 1920-1930,1950-1970,1980-2005 and 2005. Regardless of the definition, there are three important time nodes: The founding of 1949, 1978 years of reform and Opening-up and the fifth Plenary Session of the 16th CPC Central Committee in 2005. In the 30 years since the founding of the PRC, although the "goal of building a new socialist countryside" was clearly put forward in the three meetings of the 1956-year NPC, the agricultural auxiliary industry and the two-yuan pattern of the rural auxiliary cities made the gap between urban and rural areas widening, and the strict household registration system plus the two-element pattern makes the gap between the urban and rural areas widening, the strict household registration system and the restriction of the urban and rural product circulation, which leads to the problems of the three agricultural issues, and becomes the prominent feature of this stage. The reform and opening stage from the initial family contract to the well-off construction, fully mobilize the enthusiasm of the farmers at the same time the overall income also increased, the farmer's spiritual life is also gradually enriched. But in the late 90, as the market economy continued to increase the gap between urban and rural areas. The fifth Plenary Session of the 16th CPC Central Committee 2005 adopted the "Eleven-Five years outline proposal" proposed an important 20-word policy "production and development, well-off life, township wind civilization, tidy clean, management democracy", marking the new socialist rural construction into a fresh stage. These five requirements are the guiding ideology of the new rural construction, embody the organic unification of society, economy, culture and the construction of rural style, which are the coping strategies of the three agricultural problems under the background of harmonious society.

\section{Characteristics of Rural Landscape}

Since the reform and opening up, diversification trend has appeared in the rural industrial structure and social formation.With the development of economy, large-scale 
construction activities spread in the countryside spontaneously and consciously thus rural landscape has undergone significant changes which are reflected in the diversification of rural settlement types, the change of land use and material space in rural areas brought about by the change of industrial structure, as well as the change of people's way of life.

For a long time, agriculture, forestry, animal husbandry, fishery are the main body of rural landscape, as well as the leading factors of the industrial structure of rural economy. However, great changes have taken place in the industrial structure of the countryside since the reform and opening up. The drastic changes of the rural society and the gradually declined proportion of traditional agriculture are obvious among them. The traditional agricultural economy is an industrial activity characterized by family individual agriculture and manual work. Its function is mainly to provide the material foundation for the family which is the life guarantee.As the development of urbanization, the traditional agriculture has little significance to the villagers' life support due to the low economic benefits, and the industrial structure of many villages has been changing quietly. The type of village is divided from agriculture-based one to that based on non-agricultural industry. According to the experience of the world economic development, after the urbanization achieved, the industrial structure will enter the stage of accelerated differentiation. With the reform of rural economic system and the development of commodity economy, rural industrialization and urbanization in developed areas have entered the stage of accelerated development.Taking Zhejiang as an example, the level of urbanization has increased from $51 \%$ in 2002 to over $70 \%$ in 2009 . The proportion of secondary industry and tertiary industry is increasing, while the proportion of primary industry is gradually decreasing. At present, rural settlement types can be divided into agriculturalbased, industrial-based and tourism-based according to the features of its main industrial structure as different types displaying different landscape characteristics.

\section{Space construction of rural human settlement environment}

Space construction is a comprehensive embodiment of the ways, methods and technical means used by human beings to use natural environment, social economy, regional culture and productive life. Through the cognition and construction of the living environment, human beings constantly adapt to the social thought and demand, and gradually form an organic system of ecology, production and life. In the system, the elements of different types, different forms and different natures have their own development law and evolution process, and the human beings use these rules and processes to coordinate, two times cognition and function innovation to reflect different demands and the origin of human habitation.
The process of human settlement is influenced by multiple factors, showing different ways of settlement, and the role of space carrier of natural environment is especially prominent. Human beings in the use and enjoyment of the environment at the same time, constantly adapt to, change the environment. As the starting point of human settlement, rural settlement exudes the original taste, confirms the interdependence of human and space environment, and its location characteristics and spatial pattern embody human wisdom and courage.

\subsection{Space elements}

Influenced by the regional production life style and geographical conditions, the settlement form is mainly influenced by natural factors such as topography, landform and climate, and forms the typical steppe settlement form, which is composed of grassland, forest, river, dwelling, road and cattle pen. Due to the spatial dispersion and low-density population, the steppe settlements often appear scattered distribution characteristics, forming a point-like or flaky. In the process of formation and evolution of grassland settlements, religion, grassland and livestock become the typical elements of spatial form. With the change of production style and system, these typical spatial elements are also changing.

\subsection{Mode of activity and construction}

As a embodiment of human adaptation to the environment, architecture is the support of human production and life activities, mainly manifested in the environment, cost, technology and other aspects. The qualification of natural environment, the demand of function, the choice of material and the identity of culture can be said as the gene of construction entity, and it is reflected by human intelligence in the special regional building system.

\section{Development trend of Rural Landscape Construction}

"Poetic dwelling" is the ideal of people all the time. Instead of more and more similar cities constructed of concrete, the countryside, which allows people to enjoy the nature and carries Chinese traditional civilization, is more likely to be the ideal habitat. In terms of development orientation, the countryside can neither imitate the city's trajectory and lose its own characteristics, nor can it stand still and refuse to make progress. In the future, the countryside should complement the city's resources through the reconstruction of nature, production and life, so as to realize urban-rural integration. The possible trends are as follows.

8.1.A Settlement under the Concept of Slow Life

\subsection{Rural location and spatial pattern}


Through the promotion of the concept of slow life, during the construction and protection of the space of it, the countryside can be used as the balance point of rapid urban life. In economically developed areas, people's requirements for the quality of life are constantly raised in the process of rapid urban-rural integration and the proportion of tertiary industry serving the city is constantly increasing, and the "slow city", which can provide natural landscape as well as convenient urban life, is the most likely optimization direction of the rural areas, paying more attention to ecology and nature and the optimal integration of systems and efficient use of resources, which is more conducive to the long-term development of the economy and better to improve the quality of life of residents

\subsection{Ecological Safeguard and Buffer between Cities}

The model of German regional parks takes the construction of villages into the overall consideration of the whole region. Through the establishment of common regional sewage management institutions, the improvement of internal traffic conditions in regional parks, tourism services such as catering and accommodation, the construction of infrastructure and the development of markets, residents there have been provided with a special place for leisure and the entire regional economy and rural landscape development were promoted effectively. In the areas rich in landscape resources, it is of great significance for the development of urban and rural areas to integrate the villages along roads, rivers and scenic spots into a leisure land for people, as well as as ecological safeguard and buffer between cities.

\subsection{Transformation of Rural Landscape Construction Method}

The method of landscape construction should be applicable to social development demand. Since the 20th century, rural industrial structure, rural settlement types, land use and material space, as well as people's way of life have undergone profound changes and that of rural landscape are rapid and intense. In the context of the social transformation, to synthesize all elements in terms of ecology, production and life and to integrate multidisciplinary knowledge, we need to make decision in line with local conditions and adopt operational planning methods. In accordance with the requirements of sustainable development, some scholars also began to put forward some new ideas and concepts in landscape construction methods and put them into practice, such as ecologicalization, democratization, low carbonization and so on, which are summarized as follows.

\subsection{Ecologicalization Direction}

With the proposal of sustainable development, the study of ecological construction and ecological balance in pursuit of harmony between human and nature has been carried out in the construction of cities and villages. For example, Song $\mathrm{Ku}$ of Tsinghua University put forward a holistic view of ecological architecture based on some theories and concepts of ecology in his doctoral thesis "The study of Architectural Design based on Nature and Ecology." At the same time, the concepts of ecosystem structure framework and bioclimatic buffer layer are put forward, and the ecological architectural design strategy is discussed taking the design of agricultural house on Shuangshan Island in Zhangjiagang as an example and combined with the specific climate and environment conditions in southern Jiangsu.

\subsection{Democratization Direction}

The direction of democratization is an overall construction method aimed at the coordination and symbiosis of interests. With the deepening of rural practice and after the preliminary observation on the ecological pattern of landscape, people are more and more aware of the village, in the final analysis, belongs to the villagers and rural landscape is far from a matter of aesthetics or ecology, so people begin to pay more attention to the balance of interest pattern, and put forward the corresponding strategies and methods for the construction of rural landscape from the perspective of rural sociology.

Academician Wang Xiaodong of Xinjiang Architectural Survey and Design Institute, in the project of "Protection and renovation of Aho neighborhood in Luoshilaocheng District", holds that the protection and renovation of residential buildings not only involves to architecture and planning, but also involves to the whole social ecology and structural system. Therefore, it is not advisable to make great changes in construction and force emigration which may destroy the original handicraft, commercial and interpersonal structures. In terms of reconstruction mode, the planning and design should insist on maintaining the original overall style as much as possible, and break through the traditional mode, in which the managers and designers undertake the whole things. Instead, each household residents shall participate in the design. In the view of architects, the style and features of the old urban area is a combination of architecture, living habits, and national habits. It has a dynamic development process in which new ideas, new technologies and new ways are constantly mixed with the original set. And its success or not depends on the level of villagers' participation as well as the concept, attitude and working style of the managers and designers."

\subsection{The Sustainable Development Direction of Low Carbonization}

In Copenhagen climate change conference 2012, the Chinese government released the controlled emissions target of greenhouse gas that, by 2020 , carbon dioxide emissions per unit of GDP are supposed to fall $40 \%$ to $45 \%$ year on year. Proposed by our government, lowcarbon development model enters into people's vision 
and become a new hot spot. A key project of the National Natural Science Foundation of China, "Research on the Construction System of Low-Carbon Rural Residential Environment in the Yangtze River Delta", lead by Professor Wang Zhu of Zhejiang University from 2013 is in progress. The project faces the infiltration of the high-carbon behavior of urban construction into the rural areas and, from the perspective of "low carbon construction", aims at rectifying the misunderstanding of high carbon in rural construction in order to provide scientific support for the construction of low carbon rural human settlement environment based on the goal of "low carbon community" and guide the low-carbon transformation of communities.

\section{Sustainable development of rural human settlement environment}

\subsection{From the strong as to the humble inaction}

The people of the rural society in the same piece of land, born in here, grow in here and died in here. The agricultural mode of production determines the people for the climate, geographical location and other objective conditions of the great dependence. They have not enough strength to contend with the nature of the situation, took the way to adapt to nature, although at the time of the historical conditions is a kind of helpless, but at the same time is a wise choice, reflecting a kind of inaction of the construction concept. To some extent, the formation of this idea is closely related to the life style or cultural form of Chinese ancient farming.

The current rural construction is filled with too many rural lives outside of the "utilitarian as" heart, the rapid construction of many problems, the urgent need for a solution. In this context, the idea of inaction has important referential significance. The thought of inaction, which is characterized by strong interactive thinking, is another set of the diversity in the process of evolution. It provides a kind of reverse, transposition angle for people to think about problems. The road to the answer is not limited to the inherent routines, not only does not weaken the human initiative, but it can promote the evolution of thinking in a direction of innovation. In addition, the thought of inaction is a kind of thinking mode advocating nature to follow the natural law, which leads people to adopt a kind of attitude to the external environment in the process of recognizing nature and transforming nature, and thinks that objective condition is the vane of the subject consciousness, and any way of behaving against the natural law is the result of More importantly, the thought of inaction, as a complex way of thinking, can guide builders to transform contradictory opposing relations into a cooperative attitude. This kind of antagonism exists between the human development and the limited natural resources, also exists between the village builders and the villager main body, the inaction construction view through the compound various factors and the main body's way achieves to the contradictory difference softening. This way of thinking beyond the two-yuan opposition is also the essence of "inaction" wisdom. With the heart of inaction to integrate into the village construction, with tasteless heart to taste the local culture, with the use of useless for the big use, will itself from the strong controller into humble learners, is as the current rural construction participants should complete the selfexamination.

\subsection{From local spontaneous to cultural consciousness}

As one of the most complete regions of Chinese regional culture, rural settlements have not only attracted extensive attention in the field of research but also become the prototype of design. The formation of this concern is not only the cultural value of the village settlement itself, but also the simple living form is disappearing and changing in an uncontrollable way. The traditional construction means, the cultural dissemination way as well as the external environment factor function make the local culture gradually form in a kind of spontaneous state. However, the tide of globalization, the advancement of urbanization and the acceleration of economic development make the original living form and the cognitive structure of the occupants' change, and the infiltration of the foreign culture has stimulated the appearance of the alienation of the rural settlement in a certain level. The emergence of these phenomena has already deviated from the original cultural attribute under the limit of existence, more is a manifestation of the concept level and the cognitive stratification, but it does represent a special regional phenomenon in the present. Therefore, only from the form to judge the merits of the phenomenon is clearly not comprehensive, instead, we should fully explain the rural construction in the new period, and analyze the relationship between cognition level and social culture from the main body of rural settlement construction and residence.

\section{References}

1. Wu Liangyong, an Introduction to human settlements environment Science, Beijing: China Construction Industry Press: 2001.38

2. Li Xiaofeng, vernacular architecture-interdisciplinary theory and method, Beijing: China Construction Industry Press, 2005

3. Wang Dong, communal construction of rural settlements and integration of architects, Times architecture, 2007 (04), 16-21

4. Wangzhu, Fan Liyang, Chen Zongyan, New Village "ecological human habitat" model--a case study of the rural areas of Jiangnan, China, 2011 (4) 22-26

5. ANSI B. AISC 360-10-Specification for Structural Steel Buildings[J]. Chicago AISC, 2010.

6. GB. 50010-2003, Code for design of steel structures[S]. Beijing: China Architecture \& Building Press, 2003. 